\title{
Mucociliary Transport in Living Tissue: The Two-Layer Model Confirmed in The Mussel Mytilus edulis L.
}

\author{
PETER G. BENINGER ${ }^{1, *}$, JOHN W. LYNN ${ }^{2}$, THOMAS H. DIETZ ${ }^{2}$, \\ AND HAROLD SILVERMAN ${ }^{2}$ \\ 'Département de Biologie, Université de Moncton, Moncton N.B. Canada E1A 3E9; and \\ ${ }^{2}$ Department of Zoology and Physiology, Louisiana State University, Baton Rouge, Louisiana 70803
}

The present study combined video confocal laser microscopy (1) and tissue reflectance and autofluorescence to visualize mucus position and mucociliary transport in excised living gill tissue from the blue mussel Mytilus edulis. Rafts of mucus and embedded particles were transported atop a periciliary space traversed by frontal cilia, which engaged the mucus layer and moved it during the effective stroke, disengaging and completing the cycle during the recovery stroke. These results confirm the twolayer model for mucociliary transport in the mussel gill. Given the conservative nature of ciliated epithelial structure and function (2,3), and the structural similarity of mucociliary surfaces as diverse as terrestrial vertebrate respiratory epithelium and molluscan gill, the two-layer mechanism of mucociliary transport may be a general feature of Metazoan biology.

Mucociliary transport is a common mechanism of particle movement along epithelial surfaces in many Metazoan taxa $(4,5,6)$. Examples include cleaning of respiratory surfaces in both terrestrial vertebrates and aquatic invertebrates, as well as suspension-feeding in aquatic invertebrates. Indeed, transport of material on terrestrial vertebrate epithelia appears to be impossible without the intervention of mucus as a mechanical coupler $(7,8)$. In humans, disorders of mucociliary transport are manifested in diseases such as cystic fibrosis and chronic bronchitis (9). The mucus layer also reduces dehydration of respiratory surfaces in terrestrial animalsa prerequisite for life on land. Although the observational techniques employed to date have not yielded con-

Received 27 January 1997; accepted 7 May 1997.

* Current address: Laboratoire de Biologie Marine, Faculté des Sciences, Université de Nantes, 44322 Nantes, Cédex 3, France. sistent results, some indirect data support a two-layer model, with a viscous mucus layer atop a less viscous periciliary fluid, within which the cilia beat $(4,8,10,11$, $12,13)$. However, the exact position of mucus and mechanism of mucociliary transport have never been observed directly in living tissue. Previous attempts to directly observe mucociliary transport have been confounded by the transparency of mucus and the inability to achieve sufficient field depth to visualize both cilia and three-dimensional transport simultaneously. In the present study, $1-\mu \mathrm{m}$ fluorescent particles were used to help render mucus visible after its incorporation in the mucus raft, and the confocal laser technique was employed to visualize fluorescence and autoreflectance with high resolution and achieve sufficient and selectable field depth in live preparations.

Excised bivalve gill tissue is an ideal preparation for the microscopic observation of mucociliary transport, since it is normally immersed in an aqueous medium and ciliary activity remains intact for prolonged periods (14). Pieces of the posterior extremity of each of the four demibranchs of adult Mytilus edulis were excised and observed using a modified video confocal laser technique (1); these conditions enabled the visualization of mucus, direction of water flow, and particle transport.

Mucus on the mussel gill was located atop the frontal cilia of each filament, between the apposing rows of latero-frontal cirri (Figs. 1-4). The spatial configuration of the mucus was in the form of rafts that varied from 10 to $25 \mu \mathrm{m}$ in thickness, tapering to occasional slight gaps. Such a large range of thickness could be due to unequal secretion, unequal distribution on the surface, or both, as well as to the differential states of hydration of mucus secreted at slightly different times. The physiological stress of sectioning and mounting probably also in- 

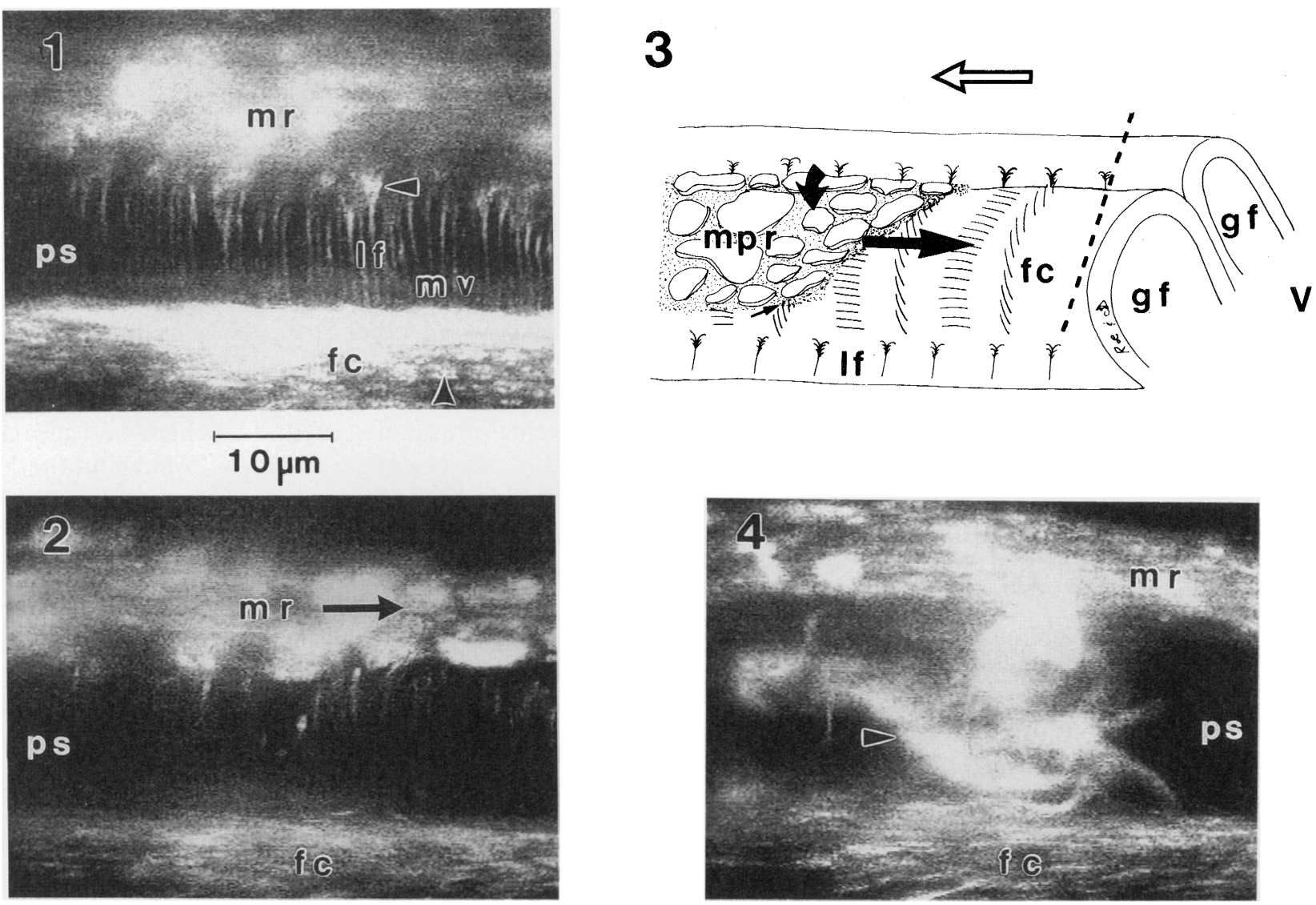

Figures 1-2. Lateral view of frontal surface of Mytilus edulis gill filament. The two-layer structure is evident, comprising the periciliary space (ps), within which the frontal cilia ( $\mathrm{fc}$ ) beat, and a mucus raft ( $\mathrm{mr}$ ), propelled by the frontal cilia (arrow). The latero-frontal cirri (If) are visible when within the plane of focus. The splayed cirral ' $V$ ' (upper arrowhead) belongs to one of the shorter cirri, which does not extend over the raft surface. The $\mathrm{V}$ width, nuclei (bottom arrowhead) and the height of the microvillar layer $(\mathrm{mv})$ were used for scale calibration.

Figure 3. Interpretive drawing (not to scale) showing two transversally-sectioned gill filaments (gf), latero-frontal cirri (If), frontal cilia (fc), position and direction of movement of mucus raft with included particle masses (mr, straight solid arrow), direction of latero-frontal cirral beat (curved solid arrow), direction of pallial fluid flow over filaments (hollow arrow), and direction of frontal cilia effective stroke (small arrow). Dotted line represents plane of view in Figs. 1, 2, 4. V, ventral orientation.

Figure 4. Live crustacean larva (arrowhead) trapped within the periciliary space (ps), between frontal cilia ( $\mathrm{fc}$ ) and mucus raft (mr).

Scale bar valid for Figs. 1, 2, 4.

creased the secretion of mucus and thus the thickness of the rafts, and the highly reflective particles may have presented a halo effect that exaggerated the raft thickness. The mucus rafts were transported in the normal direction by the frontal cilia, i.e., toward the ventral margin of the gill (Figs. 1, 2); although observations of their entrainment into the ventral groove were not made, this is the only available destination. It was possible to observe beating of individual frontal cilia only at a recording speed $\geq 120$ frames/s, and even under these conditions the uniform contrast presented by the many surrounding cilia precluded detailed observations of individual ciliary beat or clear still micrographs. Video sequences showed that the tips of individual cilia interacted with the mucus rafts during the effective stroke and disengaged and completed the cycle below the rafts during the recovery stroke. Both the frontal cilia length (about 19-24 $\mu \mathrm{m}$ ) and the periciliary space (13.3$15.3 \mu \mathrm{m})$ were considerably larger than the corresponding cilia length and putative periciliary space $(4-6 \mu \mathrm{m})$ in the terrestrial vertebrate respiratory epithelium $(4,13)$; this may be a consequence of the presence of water on both sides of the raft in the aquatic medium of the mussel gill. The frontal cilia length is in line with or only slightly larger than that suggested by previous data for $M$. edulis (15), when curvature, fixation shrinkage, and the height 
of the microvillar layer are accounted for. In the present study, scanning electron microscopy of fixed filaments corrected for shrinkage, confocal laser microscopy, and light microscope measurements on live desquamated frontal cells gave good agreement for frontal cilia lengths. The 4-9 $\mu \mathrm{m}$ by which the frontal cilia length exceeded the periciliary space height probably allows both for bending during the effective stroke and for sufficient insertion into the mucus raft.

These observations confirm the two-layer model for mucociliary transport and position on the ciliated epithelium of the mussel gill. The mechanism for mucus positioning above the periciliary space is not yet known, but is probably a combination of capillary action through the periciliary space upon secretion and the subsequent inability of the newly hydrated and cross-linked macromolecules to penetrate between the dense cilia cover (16). The frontal cilia are thus free to beat in the much less viscous (18) periciliary fluid (which is continuous with the water in the palleal cavity through the gaps in the mucus rafts), and the detailed characteristics of two-layer mucociliary transport (4) are thus consequent. The robustness of the two-layer spatial organization was evident from observations of large pieces of detritus and even an apparently live trapped crustacean larva that presumably entered the periciliary space through a gap in the rafts (Fig. 4).

The observations of the present study show that the latero-frontal cirri beat perpendicular to the mucus raft movement (Fig. 3). Previous reports (1) and work in progress show that these cirri intercept suspended particles and deviate them onto the frontal surface; the present observations suggest that the particles are in fact deviated onto the mucus raft, since most cirral tips extend several micrometers above the raft (deduced from the absence of cirral 'V's at the distal extremities in Fig. 2). This probably represents a major mode of particle capture and initial transport in the mussel-a mechanism that has eluded direct observation to date in any bivalve species.

The role of mucus in bivalve suspension-feeding has been a subject of considerable controversy for decades, focusing on whether it is used in normal feeding or only in the cleaning of feeding surfaces, i.e., the production of pseudofeces $(17,18,19,20,21,22)$. Video endoscopy and direct sampling of the contents of the ciliated tracts of bivalves displaying relaxed, normal feeding behavior has clearly demonstrated that mucus is involved in both cleaning and feeding $(5,21)$. Subsequent mucocyte mapping has revealed that different types of mucus are used in different anatomical contexts, which themselves are directly related to the different aspects of particle processing $(23,24,25,26)$. In addition, the continuum of mucocyte distribution extends well into the esophagus, beyond the sites of pseudofeces production (27). Recent opposition to this body of data centers on the conjecture that artifactual secretion of mucus might occur in any non-natural situation (22). These objections would preclude virtually all studies of bivalve feeding mechanisms, as well as most other physiological investigations. Similarly, other workers (28) discount in vitro studies altogether, even though some aspects of particle processing have been shown to be unaffected by dissection (25). In vitro studies and other manipulations impose limitations, as do all investigative techniques, but their utility should not be arbitrarily rejected (29).

The chief morphological and biochemical features of ciliary beat are essentially identical throughout the Metazoa (30), as are the structure and function of mucociliary epithelia $(2,3,4,13)$. It is thus likely that (with the exception of several phyla that lack cilia) the two-layer mechanism of mucociliary transport is a general feature of Metazoan biology. This simple but elegant two-layer system also serves important functions other than particle transport in the Metazoa. The periciliary fluid layer in terrestrial vertebrates, for example, has assumed a critical role in gas exchange through an aqueous medium and as a solvent for molecules detected by olfaction. The two-layer system is crucial to both the functioning and the maintenance of such basic biological processes.

\section{Acknowledgments}

We thank Mad. R. Larocque and S. C. Dufour for their assistance with Figure 3; MM. N. Vienneau and L. Blanchard for help with video-to-still transfer; and Ms. J. Cherry for proofreading and-with R. Bouchard-for providing technical assistance in the Life Sciences Microscopy Facility. We are grateful to Prof. M. Sleigh for discussions and critical review. This research was funded by an operating grant from the Natural Sciences and Engineering Research Council (Canada) to PGB, and by Louisiana Sea Grant NA46RG0096 Project R-ZMM-1.

\section{Literature Cited}

$\rightarrow$ Silverman, H., J. W. Lynn, and T. H. Dietz. 1996. Particle capture by the gills of Dreissena polymorpha: structure and function of latero-frontal cirri. Biol. Bull. 191: 42-54.

2. Meyer, F. A., and A. Silberberg. 1978. Structure and function of mucus. Pp. 203-218 in Ciba Foundation Symposium, Vol. 54, Elsevier Press, Amsterdam.

3. Fawcett, D., and K. Porter. 1954. A study of the fine structure of ciliated epithelia. J. Morphol. 94: 221-281.

4. Sleigh, M. A., J. R. Blake, and N. Liron. 1988. The propulsion of mucus by cilia. Am. Rev. Respir. Dis. 137: 726-741.

5. Beninger, P. G., J. E. Ward, B. A. MacDonald, and R. J. Thompson. 1992. Gill function and particle transport in Placopecten magellanicus (Mollusca: Bivalvia). Mar. Biol. 114: 281-288.

6. Beninger, P. G., S. St-Jean, and Y. Poussart. 1993. Gill function 
and mucocyte distribution in Placopecten magellanicus and Mytilus edulis. Mar. Ecol. Prog. Ser. 98: 275-282.

7. Sadé, J., N. Eliezer, A. Silberberg, and A. C. Nevo. 1970. The role of mucus in transport by cilia. Am. Rev. Respir. Dis. 102: 48-52.

8. Silberberg, A., F. A. Meyer, A. Gilboa, and R. A. Gelman. 1977. Function and properties of epithelial mucus. Pp. 171-180 in $\mathrm{Ad}$ vances in Experimental Medicine and Biology, Vol. 89, M. Epstein and O. V. Parke, eds. Plenum Press, New York.

9. Braunwald, E., K. J. Isselbacher, R. G. Petersdorf, J. D. Wilson, J. B. Martin, and A. S. Fauci, eds. 1987. Harrison's Principles of Internal Medicine, 11 th ed. McGraw-Hill, New York.

10. Lucas, A. M., and L. C. Douglas. 1934. Principles underlying ciliary activity in the respiratory tract. II. A comparison of nasal clearance in man, monkey, and other mammals. Arch. Otolaryngol. 20: 518-541.

11. Yates, G. T., T. Y. Wu, R. E. Johnson, A. T. W. Cheung, and C. L. Frand. 1980. A theoretical and experimental study on tracheal muco-ciliary transport. Biorheology 17: 151-162.

12. Blake, J. R., and G. R. Fulford. 1984. Mechanics of ciliary transport. Physico. Chem. Hyd. 5: 401-411.

13. Sleigh, M. A. 1989. Adaptations of ciliary systems for the propulsion of water and mucus. Comp. Biochem. Physiol. 94A: 359-364.

$\rightarrow$ Gardiner, D. B., F. S. Turner, J. M. Myers, T. H. Dietz, and H. Silverman. 1991. Long-term culture of freshwater mussel gill strips: use of serotonin to affect aseptic conditions. Biol. Bull. 181: 175-180.

$\rightarrow$ Owen, G. 1974. Studies on the gill of Mytilus edulis: the eu-laterofrontal cirri. Proc. R. Soc. Lond. Ser. B 187: 83-91.

16. Meyer, F. A., and A. Silberberg. 1980. The rheology and molecular organization of epithelial mucus. Biorheology 17: 163-168.

$\rightarrow$ MacGinitie, G. E. 1941. On the method of feeding in four pelecypods. Biol. Bull. 80:18-25.

18. Jørgensen, C. B. 1966. The Biology of Suspension Feeding. Pergamon Press, Oxford.

19. Jørgensen, C. B. 1990. Bivalve Filter Feeding: Hydrodynamics,
Bioenergetics, Physiology and Ecology. Olsen \& Olsen Press, Fredensborg, Denmark.

$\rightarrow$ Haven, D. S., and R. Morales-Alamo. 1970. Filtration of particles from suspension by the American oyster Crassostrea virginica. Biol. Bull. 139:248-264.

$\rightarrow$ Ward, J. E., B. A. MacDonald, R. J. Thompson, and P. G. Beninger. 1993. Mechanisms of suspension-feeding in bivalves: resolution of current controversies by means of endoscopy. Limnol. Oceanogr. 38:265-272.

22. Jørgensen, C. B. 1996. Bivalve filter-feeding revisited. Mar. Ecol. Prog. Ser. 142: 287-302.

23. Beninger, P. G., and S. D. Dufour. 1996. Mucocyte distribution and relationship to particle transport on the pseudolamellibranch gill of Crassostrea virginica (Bivalvia: Ostreidae). Mar. Ecol. Prog. Ser. 137:133-138.

24. Beninger, P. G., and S. D. St-Jean. 1997. Particle processing on the labial palps of Mytilus edulis and Placopecten magellanicus (Mollusca: Bivalvia). Mar. Ecol. Prog. Ser. 147:117-127.

25. Beninger, P. G., S. C. Dufour, and J. Bourque. 1997. Particle processing mechanisms of the eulamellibranch bivalves Spisula solidissima and Mya arenaria. Mar. Ecol. Prog. Ser. 150:157-169.

26. Beninger, P. G., and S. D. St-Jean. 1997. The role of mucus in particle processing by suspension-feeding bivalves: unifying principles from diverse systems. Mar. Biol. (in press).

27. Beninger, P. G., M. Le Pennec, and A. Donval. 1991. Mode of particle ingestion in five species of suspension-feeding bivalve molluscs. Mar. Biol. 108:255-261.

$\rightarrow$ Ward, J. E. 1996. Biodynamics of suspension-feeding in adult bivalve molluscs: particle capture, processing, and fate. Invertebr. Biol. 115:218-231.

$\rightarrow$ Hart, M. W. 1996. Deconstructing suspension feeders by analysis of film and video. Invertebr. Biol. 115:185-190.

30. Murakami, A., and M. Sleigh. 1989. Introduction to the 2 nd International Congress of Comparative Physiology and Biochemistry. Comp. Biochem. Physiol. 94A:347-349. 